\title{
Factors Affecting Infectious Diseases Outbreaks and Possible Link with the Solar Activity
}

\author{
Maghrabi Abdullrahman $\mathrm{H}^{1 *}$ and MaghrabiMarwa $\mathrm{A}^{2}$ \\ ${ }^{1}$ National Centre for Applied Physics, King Abdulaziz City for Science and Technology, Saudi Arabia \\ 2IMSI University, Saudi Arabia
}

\begin{abstract}
Infectious diseases are a major global health problem and threat to human civilization. They have occurred throughout history and are a continuing threat to humanity and life on Earth. The outbreak and spread of infectious diseases depend on several factors: individual, physiological or immunological factors as well as social, economic, and environmental influences such as meteorological and/or cosmo-geophysical factors and climate change. Identifying these factors when they emergence is very important for detecting future pandemics. In this short paper, the social and environmental factors, focusing on the effects of solar activity on the infectious diseases, will be briefly reviewed and discussed.
\end{abstract}

\section{INTRODUCTION}

Infectious diseases have occurred throughout history. They are continuing to affect human health and have become a major global health problem. According to the World Health Organization (WHO), nearly 15\% of all annual global deaths are linked directly to infectious diseases. The spread of epidemics and pandemics depends on several factors [1-9]. These include individual, physiological or immunological factors [10-11], environmental influences such as meteorological and/or cosmo-geophysical factors, as well as social and economic factors such as accelerated globalization, increased international trade, increased human interactions with animals, and poverty [10-17]. Despite extensive scientific research and technological advances, the relative influence and multiple risks these factors effect on infectious diseases remain poorly defined and unpredictable, particularly with increasing frequency of infectious disease outbreaks. Hence, a lot of research are needed to understand the interaction between these factors before relying on any early warning system to assess the risk factors of the disease $[1,18]$.

Several investigations have been carried out to understand the influence of these factors on infectious disease outbreaks. In this paper, we have tried to present a brief summary of social and environmental factors contributing to the spread of infectious diseases based on research investigations in the last two decades. These include results that showed a possible link between infectious diseases and solar-activity related causes.

\section{Social Factors}

Social factors play an effective role in amplifying an infectious disease outbreak. Their influence on the outbreak includes the following:

a) An increase in population density (hosts of the viruses) has a certain relation with viruses' transformation and mutation and this may lead to a fast spread of infectious diseases [19-20].

b) Migration from rural to urban areas increases the probability of contact among humans and animals, creating opportunities to transform an infection disease into different types $[3,21]$.

c) An increase in human activity causes environmental degradation, which has destructive effects on the ecosystem $[15,22]$.

d) Poor standard of living conditions and substandard hygiene can contribute to the spread of the diseases such as cholera and typhoid, particularly when overcrowding occurs $[23,24]$.

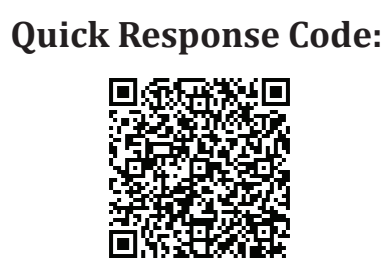

Address for correspondence: Maghrabi Abdullrahman H, National Centre for Applied Physics, King Abdulaziz City for Science and Technology, Saudi Arabia

Received: April 30, $2021 \quad$ Published: May 11, 2021

How to cite this article: Maghrabi AH. Factors Affecting Infectious Diseases Outbreaks and Possible Link with the Solar Activity. 2021- 3(3) OAJBS.ID.000277. DOI: 10.38125/OAJBS.000277 
e) An increase in the probability of a new viral strain appearing is subject to the immunity of the population $[5,11]$.

f) An increase in the number of tourists to tropical forests and/or poor countries without appropriate protection against insect bites or vaccination result in the importation of infectious diseases such as malaria and yellow fever to industrialized countries [10,17,25-27].

g) Excessive usage of antibiotics by the general population has a remarkable impact on the levels of microbial resistance $[11,28]$.

h) Deforestation and alternation of ecological zones can force animals to come in close contact with human when searching for food. This may lead to virus's transmission [9,24].

i) Using open markets to trade animals, such as in China and Southeast Asia, and relying on a home-breeding system for these animals, often leading to human interaction with poultry, pigs, etc., in the same areas, facilitates the emergence and spread of new types of viruses [29].

j) Intensifying the food production systems of companies all over the world (producing large numbers of birds to meet the demands of global markets) increases the risk of the emergence of new viral strains that are transmitted from birds to humans [29].

\section{Terrestrial and Extraterrestrial Factors}

Terrestrial (climate and environmental) factors, including weather-related aspects such as temperature and humidity changes, the observed yearly pattern of air masses, the amount of solar radiation, severe atmospheric events, air pollutant parameters, and ambient fine particulate matter and aerosols, may contribute greatly to the emergence of infectious diseases $[5,12]$.

Extraterrestrial factors (solar activity and related effects on Earth) such as the fluctuation of Earth's magnetic field (earthionosphere cavity/Schumann resonances), geomagnetic activity, variation of cosmic ray intensity, and electromagnetic changes contribute to the appearance, severity, and spread of infectious diseases outbreaks [30-36].

Most of these, however, are modulated on timescales that are either typical of Earth's seasons or longer such as extraterrestrial variables that can only explain some aspects of seasonality concerning recurring outbreaks, or the onsets of particularly violent outbreaks [10].

These factors, somehow, play direct or indirect roles in influencing the nature of the virus, acquired hosts, virushost interactions, infectious diseases viruses' stability and transmissibility. Understanding the influences of these factors will improve the predictability of the circulation and peak seasonality, crucial to conduct the appropriate early warning and long-term control strategies against the disease outbreak [29].

Air temperature and relative humidity have been the factors most explored by laboratory and observational studies. It has been established that temperature variations influence the genetic mutation of some infectious diseases such as influenza viruses [9]. However, temperature and humidity variations are subject to terrestrial and/or extraterrestrial changes, which will be discussed below.
Given the large and effective role that the sun plays in influencing the Earth and thus our lives, any slight, change in the sun's activity will have an impact on the Earth depending on the strength and intensity of this change or event. Solar activity is the period during which the number of sunspots numbers reaches its maximum, with significant increases in solar flares, coronal mass ejections, high-speed solar wind, and solar energetic particles. All solar activity is driven by the solar magnetic fields, which have an impact on the Earth.

At first, the connection between infectious diseases and solar activity seemed unrealistic. However, Alexander Chizhevsky, and later, Hope-Simpson [31] observed that there are correlations between influenza pandemics and the sunspots reaching its maximum [37]. However, the exact mechanism that explains this relationship is unclear. Recent research has shown that solar activity may directly or indirectly affect the spread and outbreak of infectious diseases through its influence on the environment or through its direct effect on the human body. Following are some of the indications that consider the link between solar activity and infectious disease outbreak.

Heliobilogical studies reported that all the infectious diseases reported between $19^{\text {th }}$ and $21^{\text {st }}$ centuries, including influenza epidemics, occurred during the periods of solar activity [29, 36-37].

Biological research has recognized that life evolved on Earth under the constant presence of Schumann resonances (extreme low frequency electromagnetic fields). This has important effects on cell functioning, although the nature of these effects is not entirely clear. During periods of solar activity, changes in the electrical and magnetic field of the Earth during geomagnetic storms usually occur, which can have a significant impact on the functioning of organs in human beings [32-39].

Solar activity affects temperature and other climate phenomena, which in turn may affect, indirectly, the migration patterns of most types of birds, influencing their arrival and departure times. As consequences, the delay in the time of arrival or departure may increase the number of birds in a specific area, thereby increasing contact among them as they will be very close to each other. Thus, it increases the competition for limited food and may also increase the chance of species overlap and virus transmission [40].

It has been established that solar activity at its peak will assist the descent of charged molecular aggregates (including viruses) from the stratosphere to the ground level [41].

Recent bio-climatological studies indicated that solar activity has an impact on the Earth's climate in terms of extreme events, such floods, droughts and storms. These factors can impose changes in infectious disease transmission cycles, population sensitivity, and the severity of the virus. The El Nino phenomenon is considered one of the most important phenomena associated with changes in solar activity. Many studies have shown that such changes during the period of solar activity affect the size and strength of these phenomena, which can in turn affect infectious disease pandemic among humans [42-43].

Bio-medical investigations have found that seasonal changes affect the body's immune system as vitamin D levels decrease due to seasonal decreases in exposure to ultraviolet (UV) radiation or due to aerosol concentrations and cloud amounts. In supporting this Maghrabi and Kudela [44] have recently studied the relationship 
between the atmospheric aerosols and cosmic rays to find that aerosol concentrations increase during the solar minimum periods due to the increases in ionizations caused by cosmic rays. These ionizations increase the cloud condense nuclei, which led to a decrease in ultraviolet radiation $[37,45]$.

\section{CONCLUSION}

Infectious diseases spread has become a major health problem, threatening humans. The spread of epidemics and pandemics of infectious diseases depends on several factors. This paper, based on the scientific investigations in the last 20 years, presented a brief summary of the social and environmental factors contributing to the infectious diseases. The most important is the evidence that suggested that solar activity has direct or indirect influences on the appearance of infectious diseases outbreak. Although there are speculations about the reality of such relationships, results have attracted the scientific community to conduct more research in this field to search for mechanisms that can explain such relationships. Close scientific cooperation between scientists from different fields is required for better understanding the interaction between these factors for assessing the multi-risk factors of infectious diseases.

In this regard, a national-scale project led by the first author of this paper has been proposed and submitted to the Ministry of Health and other research organizations in Saudi Arabia to investigate the effects of solar activity parameters on infectious diseases outbreak in Saudi Arabia.

\section{ACKNOWLEDGMENT}

We would like to thank the King Abdulaziz City for Science and Technology (KACST) for supporting this work.

\section{REFERENCES}

1. Moreens D, Folkers G, Fauci A (2004) The challenge of emerging and reemerging infectious diseases. Nature 430: 242-249.

2. Carrat F, Verge E, Ferguson N, Magali L, Simon C, et al. (2008) Timelines of infection and disease in human influenza: a review of volunteer challenge studies. Am J Epidemiol 167(7): 775-785.

3. Newman M (2002) Spread of epidemic disease on networks. Phys Rev E Stat Nolin Soft Matter Phys 66(1 Pt 2): 016128.

4. House J (2002) Understanding social factors and inequalities in health: $20^{\text {th }}$ century progress and $21^{\text {st }}$ century prospects. J Health Soc Behave 43(2): 125-142

5. McMichael A (2004) Environmental and social influences on emerging infectious diseases: past, present and future. Philos Trans R Soc Lond B Biol Sci 359: 1049-1058.

6. Taylor L, Latham S, Woolhouse M (2001) Risk factors for human disease emergence. Philos Trans R Soc Lond B Biol Sci 356: 983-939.

7. Casanova L, Jeon S, Rotula, David JW, Mark DS (2010) Effects of air temperature and relative humidity on coronavirus survival on surfaces. Appl Environ Microbiol 76: 2712-2717.

8. Chantel S, Martin LM, Tina H (2011) Impact of pollution, climate and sociodemographic factors on spatiotemporal dynamics of seasonal respiratory viruses. Clin Transl Sci 4(1): 48-54.

9. Pica N, Bouvier N (2012) Environmental factors affecting the transmission of respiratory viruses. Curr Opin Virol 2(1): 90-95.

10. Dowell S (2001) Seasonal variation in host susceptibility and cycles of certain infectious diseases. Emerg Infect Dis 7(3): 369-74

11. Levy S (1992) The antibiotic paradox: how miracle drugs are destroying the miracle. Plenum Press, USA.
12. Eisenberg J, Cevallos W, Ponce K, William C, Karina P, et al. (2006) Environmental change and infectious disease: how new roads affect the transmission of diarrheal pathogens in rural Ecuador. Proc Natl Acad Sci USA 103(51):19460-19465.

13. Bansal S, Grenfell B, Meyers L (2008) When individual behavior matters: homogeneous and network models in epidemiology. J R Soc Interface 4(16): 879-891.

14. House J, Landis UD (1988) Social relationships and health. Science 241(4865): 540-545

15. Cohen J, Wilson M, Aiello A (2007) Analysis of social epidemiology research on infectious diseases: historical patterns and future opportunities. J Epidemiol Community Health 61(12): 1021-1027.

16. Qu J, Wickramasinghe N (2020) The world should establish an early warning system for new viral infectious diseases by space-weather monitoring. Med Comm.

17. Holtgrave D, Crosby R (2003) Social capital, poverty, and income inequality as predictors of gonorrhoea, syphilis, chlamydia and AIDS case rates in the United States. Sex Transm Infect 79(1): 62-64

18. Reiner R, Smith D, Gething P (2015) Climate change, urbanization and disease: Summer in the city.. Trans R Soc Trop Med Hyg 109: 171-172.

19. Goldmann D (2000) Transmission of viral respiratory infections in the home. Pediatr Infect Dis J 19(10 Suppl): S97-S102.

20. Schaffer F, Soergel M, Straube D (1976) Survival of airborne influenza virus: effects of propagating host, relative humidity, and composition of spray fluids. Arch Virol 51(4): 263-273.

21. Tellier R (2009) Aerosol transmission of influenza A virus: a review of new studies. J R Soc Interface. 2009 Dec 6;6 Suppl 6(Suppl 6): S783-S790.

22. Jonathan AP, Peter D, Gary MT, Alonso AA, Mary P, et al. (2004) Unhealthy landscapes: Policy recommendations on land use change and infectious disease emergence. Environ Health Perspect 112(10): 1092-1098.

23. Butler C (2000) HIV and AIDS, poverty and causation. Lancet 356(9239): $1445-1446$

24. Morse S (1995) Factors in the emergence of infectious diseases. Emerg Infect Dis 1(1): 7-15.

25. James KT, John T, Munguti K, Mark M, Nick J, et al. (2002) Diarrhoea and effects of different water sources, sanitation and hygiene behaviour in East Africa. Trop Med Int Health 7(9): 750-756.

26. Moser M, Bender T, Margolis H, Noble GR, Kendal AP, et al. (1979) An outbreak of influenza aboard a commercial airliner. Am J Epidemiol 110(1): 1-6

27. Weber M, Mulholland E, Greenwood B (1998) Respiratory syncytial virus infection in tropical and developing countries. Trop Med Int Health 3(4): 268-280.

28. Levy S, Marshall B (2004) Antimicrobial resistance worldwide: causes, challenges and responses. Nat Med 10(12 S): S122-S129.

29. Abdullrahman H, Marwa A (2020) The effects of solar activity and geomagnetic disturbance on human health. OAJBS 2(5): ID.000203.

30. Yeung J (2006) A hypothesis: sunspot cycles may detect pandemic influenza A in 1700-2000 A. D. Medical Hypotheses 67(5): 1016-1022.

31. Hope-Simpson R (1978) Sunspots and flu: a correlation. Nature 275: 86.

32. Cherry N (2002) Schumann resonances, a plausible biophysical mechanism for the human health effects of Solar/Geomagnetic Activity. Natural Hazards 26: 279-331.

33. Zaporozhan V, Ponomarenko A (2010) Mechanisms of geomagnetic field influence on gene expression using influenza as a model system: Basics of physical epidemiology, Int J Environ Res Public Health 7(3): 938-965.

34. Palmer S, Rycroft M, Cermack M (2006) Solar and geomagnetic activity, extremely low frequency magnetic and electric fields and human health at the Earth's surface. Surv Geophys 27(5): 557-595. 
35. Belova N, Acosta AD (2015) The effect of extremely low frequency alternating magnetic field on the behavior of animals in the presence of the geomagnetic field. J Biophys (9): 423838.

36. Santini M, Rainaldi G, Indovina P (2009) Cellular effects of extremely low frequency (ELF) electromagnetic fields. Int Rad Bio 85(4): 294-313.

37. Rottman G, Woods T, Snow M, DeToma G (2001) The solar cycle variation in ultraviolet irradiance. Adv Space Res 27(12): 1927-1932.

38. Gachari F, Mulati D, Mutuku J (2014) Sunspot numbers: Implications on Eastern African rainfall. South African Journal of Science 110: 1-2.

39. Welliver R (2007) Temperature, humidity and ultraviolet B radiation predict community respiratory syncytial virus activity. Pediatr Infect Dis J 26(11S): S29-S35.

40. Wickramasinghe N (2020) Space weather and pandemic warnings? Current Science 117(10): 1554.
41. Wickramasinghe N, Tokoro G, Wainwright M (2015) The transition from earth-centred biology to cosmic life. Journal Astrobiology Outreach 3: 1 .

42. Zaraket H, Saito R, Tanabe N, Kiyosu T, Hiroshi S (2008) Association of early annual peak influenza activity with El Nino southern oscillation in Japan. Influenza and Other Respiratory Viruses 2(4): 127-130.

43. Mazzarella A, Giuliacci A, Pregliasco F (2011) Hypothesis on a possible role of El Niño in the occurrence of influenza pandemics. Theoretical and Applied Climatology 105: 65-69.

44. Maghrabi A, Kudela K (2019) Relationship between time series cosmic ray data and aerosol optical properties: 1999 - 2015. J solar Terrestrial Physics 190: 36-44.

45. Hayes D (2010) Influenza pandemics, solar activity cycles and vitamin D. Medical Hypotheses 74(5): 831-834. 